\title{
Scenarios in HIV/AIDS prevention research: Insights from literature and research in Botswana
}

\author{
Mabel K. M. Magowe \\ School of Nursing, University of Botswana, Gaborone, Botswana \\ Email: magowem@mopipi.ub.bw
}

Received 24 January 2013; revised 26 February 2013; accepted 6 March 2013

\begin{abstract}
The difficulties in communication about sexualityrelated matters in HIV prevention require appropriate research approaches. Scenarios can be useful in qualitative, quantitative research methods and interventions related to sensitive cognitive issues of human sexuality. This paper presents an analysis of the use of scenarios in HIV/AIDS prevention research from the literature and empirical evidence. Examples of scenario-based instrument development research studies in safer sex communication for the prevention of HIV/AID by Kalichman (2000) and Magowe (2006) are provided. A computer-based search of articles addressing the use of case scenarios in research was conducted on Google and Google scholar, using the following search terms: "case scenarios", "scenarios in research", case scenarios in safer sex negotiation: "case scenarios in safer sex communication", "case scenarios in dyadic communication", "partner communication", "case research", "vignettes in HIV/AIDS research", and, "sexuality related vignettes". Papers included provided the definition, purpose, components, types of scenarios, use of scenarios in safer sex communication. Examples are drawn from instruments development studies using with case scenarios. Twenty-nine documents were retrieved, and eight of these studies addressed the use of scenarios in research. Five studies were specifically on HIV prevention research, focusing on safer sex communication, negotiation or couple/partner communication. The content of the studies included the definition of scenarios, case scenarios and vignettes; purpose and use of scenarios in research. Studies showed that scenarios are useful in qualitative elicitation of themes and content for instrument development for further quantitative research. Nursing deals with sensitive and complex cognitive issues in human behavior, and therefore scenario-based research can help develop person-oriented research and interventions while protecting the individual's privacy and confidentiality.
\end{abstract}

Keywords: Scenarios in Research; Safer Sex

Communication; Sexuality Related Communication

\section{INTRODUCTION}

Heterosexual intercourse carries the highest risk of infection among sexual partners worldwide, based largely on the partner's risk behavior [1] and remains biggest challenge for HIV prevention in Botswana. In the absence of a cure the control of the epidemic has to depend largely on the prevention of sexuality related transmission of infections. Prevention strategies such as condom use and risk reduction strategies may not be effective alone [2] and should be accompanied by effective safer sex communication between sexual partners. Some studies have shown that safer sex communication between men and women influences risk reduction behaviors [3-8], intimate sexual decisions and risk reduction behaviors in sexual relationships [9]. However, research has also shown that both men and women encounter barriers in safer sex communication due to gender and cultural barriers, and inherent difficulties with this subject matter [10]. To break these barriers, use of scenarios lends itself as a useful strategy to facilitate communication in research about sensitive sexuality related matters. Because of their concrete nature, scenarios support communication between different people [11]. Scenario analysis is a new participatory and problem-oriented approach for integrating knowledge, and analyzing future response and plans in an organized way [12].

\section{PURPOSE}

This paper presents a literature review and an application of scenario vignettes in HIV/AIDS prevention research to elicit critical information when conducting research on sensitive sexuality related subject matter. The paper further shares research experience that applied scenarios in safer sex communication. The analysis includes a review of the literature to articulate description and application of case scenarios in HIV prevention research. The defini- 
tions, purpose, components, types, examples of studies and instruments with case scenario vignettes are explored. Evidence is also drawn from research studies that applied scenarios.

\section{METHODOLOGY}

A computer-based search of articles addressing the use of case scenarios in research was conducted on Google and Google scholar, using search the following search terms: "case scenarios", "scenarios in research", case scenarios in safer sex negotiation: "case scenarios in safer sex communication”, case scenarios in dyadic communication”, “partner communication”, “case research”, “vignettes in HIV/AIDS research”, and, "sexuality related vignettes". The papers provided the definition, background information, purpose, components, types of scenarios, measurement perspectives, and examples of instruments development studies using case scenarios.

\section{RESULTS}

Twenty-nine documents were retrieved from the internet, and eight of these studies addressed the use of scenarios in research. Five studies were specifically on HIV prevention research, focusing on safer sex communication, negotiation or couple/partner communication. The content of the studies included the definition of scenarios, case scenarios and vignettes; purpose and use of scenarios in research. Studies demonstrating the use of scenarios in qualitative elicitation of themes and content for instrument development for further quantitative research were identified and the results are shared.

\section{DEFINITIONS}

Scenario represent a story of situations and actions written in a narrative form, describing concrete details of real world conditions and circumstances including place, time, participants, objects like gadgets used, contents like news article etc. [11]. They describe a possible state of affairs developed over time, useful to communicate speculative thoughts about the future or its uncertainty, and different options related to outcomes for the situation under scrutiny [13]. They offer a middle-ground between speculation and reality; serve as a medium for facilitating participation use of knowledge [14]. A case scenario is as a textual or graphical description of a possible set of events that might reasonably take place in a given situation or context [15]. The scene stimulates thinking about current problems or concerns, possible occurrences, assumptions relating to these occurrences, action opportunities and risks [15]. In this context scenarios are useful in obtaining sensitive information in a participatory non-personalized manner that facilitates openness and enriches the depth of data collection.

\section{BACKGROUND}

Scenarios have been used extensively in computer and engineering sciences research to explore and resolve user problems [11,15-17] "for understanding the Old World, identification of problems and their causes, before proceeding to proposing justifiable changes for a New World” [18]. Usability research offers several good and coherent definitions for scenarios [14,18,19]. Their application in Health research is relatively minimal despite their popularity in clinical and classroom teaching.

\section{THE PURPOSE OF SCENARIOS}

Scenarios can provide a forum for arousing and opening people's minds, new emotions and thoughts about longheld internal beliefs. The use of scenarios offers a possibility to anticipate and envision the typical and significant user activity in a qualitative manner and to discuss the results with different actors [16]. They tend to be protective of the privacy of the individual especially in focus groups [13]. The approach, therefore, can maximize exploration of the many problems while protecting the privacy of the individual by presenting information in a hypothetical manner.

Scenarios can be used in social processes that prohibit or inhibit complete assessment of individuals. They can be used for elicitation/discovery and validation/refinement of data to fill the gap between the old (unknown) and new (future) worlds [15]. Case scenarios can serve as change stimulants. Whether people respond to scenarios individually or in a group, the thought process they go through can assist them to develop some goals for themselves, and possibly to make plans to reach such goals, learning from the imagined person in the scenario. People can obtain information that they can use and the consequences of using that information for themselves and significant others, which can be analyzed prior to development of any interventions on their problems. Individuals can suspend personal commitment and involvement in the actual behavior, because they do not directly impose a personal challenge, but can increase concrete progress in exploration of alternatives to the ideas being pursued. Scenarios also provide a task oriented decomposition and analysis of the problem from many perspectives, including actual trade-offs, possible developments and consequences that may facilitate or debar action.

\section{COMPONENTS OF SCENARIOS}

Scenarios consist of the following elements: 1) setting or context, or environment which is the scene from the epi- 
sode being described; 2) actors or imagined typical people whose profile is being depicted, either alone or in relationship with others; 3 ) goals and objectives: the actors are usually motivated by some goal or objective they are pursuing; 4) actions and events: a sequence of activities and events or incidents and, 5) claims: underlying questions or concerns in the events $[16,18]$. A 6th element has been added [15], being subject domain or universe of discourse: which describes the main content area being studied. This classification can also be expanded to include the influencing factors on the actions, reactions of actors, and the impact of the actions on both the actors and their environment (include significant persons in their lives).

\section{TYPES OF SCENARIOS}

This section describes the form in which the scenarios are presented and evolve [15]. Life-cycle scenarios (versus single event scenarios) can be more general, addressing the broader life cycle of humans, as opposed to specific strategic life events. In other words a scenario can be elaborate, explaining the life history of the actor in details. On the other hand a scenario can depict a cross-sectional life event addressing a specific occurrence. Interaction scenarios depict the interaction between persons and their environment or other people. These may be conversations or just interactive forces during an event. Text scenarios are presentations of text followed by a question to interpret the text. Graphic scenarios are presented as pictures, models or illustrations. Vignettes are brief histories or stories about individuals used to set the stage for discussions.

\section{THE SCENARIOS PROPOSED FOR HIV/AIDS PREVENTION RESEARCH}

Vignettes have been selected as a method of interest for qualitative in-depth exploration of sensitive issues surrounding psychosocial aspects of HIV/AIDS prevention. Vignettes have long been used in social sciences such as anthropology [19], psychology [20] and more recently in nursing research [21] and medicine [22]. Nursing Vignettes have been used in a variety of situations to explore patient's views about treatment options, to explore practitioner's decision-making processes in patient management e.g. detection and management of depression [23] and to explore practitioner's attitudes towards patients, perceptions about patients' reactions to such things as pain [24], and effects of different treatments.

Vignettes provide useful focus for discussion during individual interviews, and can act as stimulus for group discussions [25]. The information can be standardized to enable respondents to respond to the same stimulus. Vignettes do not necessarily require in-depth knowledge of the topics under study, and may be used to elicit participants' automatic response about the meanings they have on the subject. They are particularly useful when the actual people are difficult to reach and in studying potentially difficult topics such as mental illness, drug use, intimate sexual matters, by desensitizing certain aspects of these topics. People can choose to respond either from their own perspective, or from the perspective of the character thus shielding the person from embarrassment associated with ownership of the behavior being scrutinized. This permits free participation, openness and in-depth exploration of the issue. Types of vignettes include video, audio and text vignettes that have all been used for research.

\section{APPROACHES FOR DEVELOPING SCENARIO VIGNETTES}

Several frameworks are proposed in the literature for developing scenarios, which are now being applied to vignettes as a special case of scenarios. Scenarios can be developed to depict ordering one's perception about alternative future environments in which today's decisions might be played out, written in the form of stories [26]. These stories can help one confront denial by encouraging suspension of disbelief, and allowing expression of multiple perspectives of complex events. Many authors [2,27-31] seem to converge on the premise of a future perspective of developing future environmental situations, and describing the path from any given present to these future situations, to create alternatives in the case of uncertainties for complex problems that have long term effects. Re-examination of current goals and development of future goals, and assessing strategic decisions are part of the expected actions of the participating actors. Whatever the perspective may be, the steps developed by these authors for developing scenarios can be summarized as follows:

1) Identify the problem or focal issue and the influencing forces.

2) Rank the key factors by order of importance (impact analysis).

3) Determine the tasks, goals strategies and projecttions and key uncertainties.

4) Check the possible group to be associated with the forces.

5) Identify the extreme possible outcomes in terms of time frame, internal consistency, and disequilibrium among stakeholders.

6) Select the scenario logics and structure appropriate for the audience: visual, audio, textual, role-plays or games. In the case of a role-play, game or simulation, debriefing is important at the final stage.

7) Narrate the scenarios stating what happened, and 
reasons can be for the proposed situation. Give each scenario an easy name for future reference.

8) Elaborate the scenarios; probing or adding more graded scenarios on the same stimulus and assess the scenarios for relevance to the goals, internal consistency and that they are typical of the population being depicted.

\section{STRENGTHS AND WEAKNESSES OF SCENARIOS}

Strengths: Scenarios have the advantage of providing a forum for exploring multiples of possible outcomes from different actors, and thus predicting the future [13]. Furthermore, they are flexible and can be adjusted to specific situations or participant's responses [32]. They are also an appropriate way of recognizing the signals for problematic areas in the stimulus or environment, and thus help plan the future better. Scenarios open people's minds to explore their own long-held internal beliefs to unimaginable possibilities during the dialogue, especially when focus groups are used, and therefore arouse new emotions and thoughts. The learning process during discussions can improve decision-making and facilitate change. They are also protective of the personal dilemmas in the situation and thus protect the privacy of the individual unless they want to freely divulge their personal information.

Weaknesses: Scenarios can be time-consuming, and it may be difficult to select suitable participants. Interpersonal scenes may arouse traumatic and negative feeling and they may only present wishful thinking that is far from the truth or reality. Scenarios can be so remote to the person, or deliberately distanced from the self, and thus not yield authentic information about the actor's role. Providing evidence of validity and reliability for qualitative research is a difficult task, and the biggest challenge is related to internal validity, "to ensure that the situation in the vignettes genuinely portrays the phenomenon of interest and that each question pertaining to the situation is measuring the same phenomenon" $[13,21]$. An extensive review of literature, expert review of scenarios, validation and pilot-testing can help curb this problem.

\section{USE OF CASE SCENARIOS IN SAFER SEX COMMUNICATION RESEARCH}

A series of studies were conducted to develop and test the psychometric properties of scales assessing self-efficacy in men and women living with HIV/AIDS [13,21]. Data were collected as part of a larger program of research concerned with the social and emotional adjustment of people living with HIV/AIDS. Men and women were recruited from AIDS organizations, health care providers, social service agencies, community residences for people living with HIV/AIDS infectious clinics in Atlanta, Georgia. All four studies required participants to complete self-administered assessment instruments, or have the face-to-face interviews if they expressed difficulties in reading.

The first study, which applied scenarios, was a formative elicitation research to identify scenarios that would serve as the basis for measures of self-efficacy for disclosure decisions and negotiating safer sex practices in HIV positive persons. The social cognitive theory [33] and research on the assessment of self-efficacy for negotiating safer sex [34,35] served as a theoretical basis for the study. The researchers developed self-efficacy measures that would allow individuals to judge their capability within and across domain relevant activities, as well as across varying levels of situational demands. Two situational domains studied were, decisions to disclose HIV status to sex partners, and negotiating safer sex. The scenarios used were adopted [32,33]: to identify realistic and personally relevant situations within which persons confront disclosure decisions and negotiate safer sex. This assisted in drafting brief vignettes that would serve as stimulus for self-efficacy scales. Participants were also asked to generate stories from their own experiences in which they dealt with disclosure decisions and safer sex negotiation. Four graduated scenarios were developed and tested with 6 focus groups of 3 HIV positive men and 3 HIV positive women each to provide feedback on the content. More scenarios were added as a result of this testing.

Results yielded 7 sets of scenarios depicting situations in which HIV positive persons decide about disclosing HIV status (3 sets) and negotiating safer sex (4 sets). The $8^{\text {th }}$ scenario was developed to pose a more increased challenge for participants. The scenarios also yielded themes that were similar for men and women eliminating the need for gender specific scenarios and parallel forms. This study elicited themes and domains for safer sex communication and negotiation instruments with a focus on self-efficacy for sexual communication for women at risk of HIV infection and/or living with HIV.

A formative qualitative phenomenological study was conducted among young women in Gaborone, Botswana and receiving services at the city's selected maternal and child clinics [36]. The study was part of a larger predissertation qualitative elicitation pilot study sponsored by Emory University Graduate School of Arts and Sciences, The Woman's Club Memorial at Emory, Nell Hodgson Woodruff School of Nursing, Sigma Theta Tau International Nursing Honor Society, Alpha Epsilon Chapter and University of Botswana. The study was supervised by Emory University Professors: Dr. Marcia Holstad (dissertation committee chair and advisor), Dr. Ora Strickland (Co-Chair), Dr. Martha Rogers (commit- 
tee member), Dr. Colleen DiIorio (committee member) and Dr. Sally Lehr (committee member). The purpose of the study was to explore women's perceptions and beliefs about health protective sexual communication (HPSC) for the prevention of HIV/AIDS.

The women who agreed to participate in the focus groups were duly consented. Focus group sessions were held at the two clinics on scheduled dates through the assistance of a trained research assistant. Twenty-two sexually active women aged 18 - 35 years who attended $\mathrm{MCH}$ services at Gaborone city clinics participated in 3 focus groups of 8,7 and 7 . The interviews were audiotaped and transcribed verbatim to text. Field notes were also taken to augment group information. A 10 - 15 minute socio-demographic questionnaire captured personal on participants, if they had a sexual partner, participants' and partner's age in years, educational level, average annual income, marital status, the length of their relationship, whether they had an HIV test and their HIV status.

The interview/discussion guide consisted of sexualityrelated scripted scenario vignettes based on real life experiences of women in Botswana and on the investigator's knowledge of these experiences and also inspired by the works of Kalichman et al., (2001). Women examined the scenes from a variety of culturally relevant situations that they identified with. The women responded to related open-ended questions that were guided by Theory of Planned Behavior (TPB). The questions were used to probe the perceptions of women about Health Protective Sexual Communication (HPSC), beliefs about advantages and disadvantages of HPSC, about significant people in their lives who have influence in their ability to engage in HPSC, their partner's influence on HPSC, their self-efficacy for HPSC, the content they would include during HPSC, and the tactics they would use to engage their partners in HPSC and to use safer sex practices. The scenario vignettes and questions were translated to Setswana (the vernacular language) and back-translated into English for content validation. The discussions questions were moderated by the investigator and a trained assistant, probing for further information, clarifying responses, and keeping the group on track. The data analysis was conducted through qualitative description method [37], line-by-line concurrently with data collection to constantly compare responses and confirm emerging themes and sub-themes.

Most respondents were single women, often cohabiting with their male sexual partners. The majority had low education, low income and depended on their partners for livelihood. Their ages ranged between 19 and 35 years, with a mean age of 25 years. The women said they understood the scenarios and the questions clearly and that scenarios created a free and protective environment for discussion of the scenes while distancing individuals from the situation. Some women often gave personal life experiences of safer sex communication with their male sexual partner, even though they were asked to focus on the person in the scene. Twelve major themes and 20 sub-themes emerged from the qualitative analysis, and are discussed below.

Beliefs about the Consequences of HPSC (Behavioral Beliefs): Women in the study believed that HPSC with their partners could be beneficial. This was consistent with research that indicates that communication between partners was pivotal in HIV prevention [38], especially for sero-discordant couples. It could also strengthen intimacy between couples, and influence condom use decisions [39]. HIV-positive hemophiliac adolescents said communication about safer sex and sero-status disclosure was a moral thing to do [40]. The women in this study were motivated by the fact that HPSC was necessary given the threat of AIDS in Botswana rather than the morality of it. A few women believe that HPSC could be difficult, consistent with findings of other studies [39]. Positive consequences (benefits) of HPSC were partners' agreement to use safer sex practices, protection against HIV and STIs, and reduced risk of death. Some negative consequences were embarrassment, partner anger, conflict, and breaking the relationship.

Beliefs about the Influence of Significant Others (Normative Beliefs): The women in the study identified their mothers, sisters and friends as significant persons for their decisions to engage their partners in HPSC. The perception about the partners' response in safer sex communication was found to be very significant [41,42]. A high between-partner communication barriers predicted inconsistent condom use among young people at Lund University, Sweden [41].

Beliefs about Personal Capability for HPSC (Control Beliefs): The women stated that although HPSC could be difficult, they were capable of talking to their male sexual partners about safer sex, consistent with other findings that among other things, self-efficacy predicted consistent condom use [42]. In a study that explored seropositive individuals' willingness to communicate, selfefficacy and assertiveness prior to HIV infection [43] participants reported high levels of self-efficacy, which however, did not translate to actual communication. This raises concerns about confidence in self-reported behavior. Also, women reported that they encountered difficulties related to partners' non-response as a barrier to effective communication about safer sex.

Attitude towards HPSC: Women demonstrated positive attitudes towards discussing safer sex with their male sexual partners. In another study women and nonvirgin men had more positive attitudes toward safe-sex communication, which predicted having discussed con- 
dom use [44].

Perceived Subjective Norm on HPSC: Some women were capable of talking with their partners and were not hindered by thoughts of significant others in their families. Perception about the approval or disapproval of others was mentioned, but only as far as endorsing the plan for HPSC. Some women indicated fear of partner violence and rejection as a barrier towards HPSC. Knowledge about the partner and intimacy could be a factor in such responses [45].

Motivation to Comply with Wishes of Significant Others: Although women expressed some difficulties with safer sex communication, it seemed apparent that they would disregard the partner's unresponsiveness or negative attitudes towards discussions and just go ahead and introduce the topic. Women's motivation came more from female relatives, co-workers, partner and friends. Little has been written on research evidence regarding motivation to comply with perceived influence of significant others in HPSC.

Perceived Self-Efficacy: Women reported that HPSC would be easy, required little effort and would result in the use of safer sex practices. There were however, hints of difficulties and the need to use an indirect approach among some women. In the US, $77 \%$ of women aged 45 years and above in heterosexual relationships reported that it was easy to talk to their male partner about safer sex [46]. This supported this position held by younger women in Botswana who participated in this study, who were also as able to talk to their partners about safer sex.

Intention for HPSC: The women in the study indicated a strong desire and promise to communicate with their partners about selected safer sex topics, especially those that had never been discussed before. Women said they during discussion they wish to obtain sexual histories, share their own personal histories, insist on HIV testing and obtaining test results, request use of safer sex practices. None of the women mentioned the need to discuss male circumcision, multiple relationships, substance abuse or birth control and this is concerning as these are critical HIV prevention strategies,.

Use of Safer Sex Practices: Women agreed that they used safer sex practices in the past, including male and female condoms, maintaining monogamous relationships, and abstaining from sex when partner was away. Use of microbicides was unknown to the group. It is currently being studied and not yet available to the general population.

Influencing Factors and the Use of Influence Tactics: Some few women often faced difficulties with partners who were not easy to approach, and they proposed that they should be empowered through education and support from health care providers to be able to engage their partners in safer sex discussions. Some difficulties were related to men's fear of the stigma associated with living with HIV, AIDS and death, and thus failed to disclose or discuss prevention. Some women said that their partners were able to initiate HPSC, although in most instances it was attached to their fears when the woman was either known to be sero-positive or suspected as a result of illness. Women used different opportunities and enabling factors and tactics to help them to communicate effectively, and frequently obtained cooperation from their partners for further discussions and for the use of safer sex strategies.

\section{IMPLICATIONS FOR RESEARCH}

The study yielded themes and sub-themes that could be used to generate culturally sensitive scale items for quantitative measures for HPSC constructs that were appropriate and relevant to young Batswana women. The results showed that women do talk to their male sexual partners, but men control the depth and direction of discussions. Future research and interventions need to focus on ways to improve the quality and direction of discussions to achieve their preventive goal.

\section{IMPLICATIONS FOR EDUCATION AND PRACTICE}

The women's attitude towards HPSC was a significant factor in HPSC. Health care providers need to strengthen positive attitudes towards initiating and sustaining safer sex discussion and male condom use. Peer group support especially by female relatives and friends could be beneficial in assisting women to be more assertive for HPSC and female condom promotion. Health care providers need to incorporate this into women's health practice. The women's reluctance to discuss alcohol and issues related to multiple partners and risky sexual histories are most concerning given the associated threat of HIV and other STIs. Women need to appreciate the need to address these issues more frequently without nagging, even if they had been discussed previously with the male sexual partner, to maintain high consistency. Therefore, health education is needed to help women to gain confidence assertiveness in raising the issues.

Health care practitioners need to explore relationships at the couple level in order to recognize inhibitions from the partner's perspective and work with the couples to eliminate fear and promote positive relationships and communication about health protective behaviors. Couples need to be encouraged to adopt HIV preventive behaviors and to participate in HIV prevention programs. Assertiveness training can promote positive self-efficacy for HPSC and for use of safer sex practices, so that women could play a more pro-active role in protecting themselves against HIV and STI's. The above initiatives 
need to be incorporated in both pre-service and in-service programs for all health care providers, so that conscious efforts are made at all levels of clinical practice to promote preventive behavior for both men and women.

\section{IMPLICATIONS FOR POLICY}

Policy changes are required to involve men in prevention programs. Men's endorsement of the use of the female condom is important and therefore its introduction should be approached from a couple's perspective. Wider community initiatives are needed to create acceptability of the female condom and any other newer strategies for HIV prevention. Remarketing of the female condom needs to be undertaken more aggressively to give women an opportunity for a safer sex option and HIV prevention strategy that they can control. Funding will be required for this undertaking on a large scale, from government and non-governmental organizations. Training and public service policies need to re-emphasize the significant issues discussed above.

\section{REFERENCES}

[1] Wong, K.H. and Lee, S.S. (1996) Maintaining low HIV sero-prevalence among injecting drug users. The Journal of the American Medical Association, 275, 596. doi:10.1001/jama.1996.03530320020024

[2] Kimberly, J.A. and Serovich, J.M. (1999) The role of family and friend social support in reducing risk behaviors among HIV-positive gay men. AIDS Education and Prevention, 11, 465-475.

[3] DiClemente, R. (1991) Predictors of HIV prevention behavior in at risk adolescent population: The influence of perceived power norms and sexual communication on incarcerated adolescents' consistent use of condoms. Journal of Adolescent Health, 12, 385-390. doi:10.1016/0197-0070(91)90052-N

[4] Catania, J., Coates, T., Kegels, S., Thompson-Fullilove, M., Peterson, J., Marin, B., Siegel, D. and Hulley, S. (1992) Condom use in multi-ethnic neighborhoods of San Francisco: The population-based AMEN (AIDS in multiethnic neighborhoods) study. American Journal of Public Health, 82, 284-287. doi:10.2105/AJPH.82.2.284

[5] Malow, R.M., Corrigan, S.A., Canningham, S.C., West, J.A. and Penna, J.M. (1993) Psychosocial factors associated with condom use among African-American drug abusers in treatment. AIDS Education and Prevention, 5, 244-253.

[6] Catania, J., Coates, T., Golden, E., Dolcini, M. Peterson, J., Kegels, S., Siegel, D. and Fullilove, M. (1994) Correlates of condom use among black, Hispanic, and white heterosexuals in San Francisco: The AMEN l survey. AIDS Education and Prevention, 6, 12-26.

[7] Rickman, R.L., Lodico, M., DiClemente, R., et al. (1994) Sexual communication is associated with incarcerated adolescents. Journal of Adolescent Health, 15, 383-388.

\section{doi:10.1016/1054-139X(94)90261-5}

[8] Sheahan, S.L., Coons, S.J., Seabolt, J.P., Churchill, L. and Dale, T. (1994) Sexual behavior, communication: Communication, and chlamydial infections among college women. Health Care for Women International, 15, 275286. doi:10.1080/07399339409516120

[9] DiIorio, C., Duddley, W.N., Lehr, S. and Soet, J. (2000) Correlates of safer sex communication among college students. Journal of Advanced Nursing, 32, 658-665. doi:10.1046/j.1365-2648.2000.01525.X

[10] Soler, H., Quadagno, D., Sly, D.F., Riehman, K.S., Eberstein, I.W. and Harrison, D.H. (2000) Relationship dynamics, ethnicity and condom use among low-income women. Family Planning Perspectives, 32, 82-88. doi: $10.2307 / 2648216$

[11] Ranta M., Asplund, H., Saarinen, T. and Sahi, S. (2003) Scenarios and use cases in innovation prototyping of VHO play. http://www.cs.hut.fi/ ppmrg/publications/VHO/2004/Rant a_Asplund_Saarinen_Sahi_SUIPVP.pdf

[12] Swart, R.J., Raskin, P. and Robison, J. (2004) The problem of the future: sustainability science and scenario analysis. Global Environmental Change, 14, 137-146. doi:10.1016/j.gloenvcha.2003.10.002

[13] Mietzner, D. and Reger, G. (2004) Scenario approacheshistory, advantages and disadvantages. EU Seminar: New Technologies Foresight, Forecasting \& Assessment-Seville, 13-14 May 2004, 48, 61.

[14] Carroll, J.M. (1995) The scenario perspective on system development. In: Carroll, J.M., Ed., Scenario-Based Design: Envisioning Work and Technology in System Development, John Wiley, New York, 1-18.

[15] Jarke, M. (1999) CREWS Report 00-09: CREWS: Towards systematic usage of scenarios, use case studies and scenes.

[16] Hankel, O., Jakewitz, I., Pape, B. and Straus, M. (2003) Technical and Didactical Scenarios of student-centered teaching and learning. WISSPRO, S411-419.

[17] Muller, J., Creed, P.A., Waters, L. and Machin, M.A. (2000) A new scale to measure the latent functions of employment. Poster presented at the XXV11 International Congress of Psychology, Stockholm, 23-28 July.

[18] Urquhart, C. (2001) Bridging information requirements and information needs assessment: Do scenarios and vignettes provide a link? Information Research, 6,

[19] Anderson, H.H. and Anderson, G.L. (1951) An introduction to projective techniques and other devices for understanding human behavior. Englewood Cliffs, Prentice Hall.

[20] Lim, Y. and Sato, K. (2003) Encoding scenarios with design information framework for the generation of multiple aspect models for system implementation. Proceedings of the $7^{\text {th }}$ World Multi-conferences on Systematics, Cybernetics and Informatics, Orlando, July 2003, 7.

[21] Herskovits, M.J. (1950) The hypothetical situation: A technique of field research. Southern Journal of Anthropology, 6, 32-40.

[22] Gould, D. (1996) Using vignettes to collect data for nursing research studies: How valid are the findings? Journal 
of Clinical Nursing, 5, 207-212. doi:10.1111/j.1365-2702.1996.tb00253.x

[23] Ross, S., Moffat, K., McConnachie, A., Gordon, J. and Wilson, P. (1999) Sex and attitude: A randomized vignette study of the management of depression by general practitioners. British Journal of General Practice, 41, 1721.

[24] Loveman, E. and Gale, A. (2000) Factors influencing the nurses' inferences about labeling. Sociological Quarterly, 17, 555-560.

[25] Hughes, R. and Huby, M. (2002) The application of vignettes in social and nursing research. Journal of Advanced Nursing, 37, 382-386. doi:10.1046/j.1365-2648.2002.02100.x

[26] Schwartz, P. (1996) The art of long view. Doubleday, New York, 1996.

[27] von Reibnitz, U. (1988) Scenario techniques. McGrawHill, Hamburg.

[28] Schwab, P., Ceruti, F. and von Reibnitz, C. (2003) Foresight-using scenarios to shape the future of agriculture research. Foresight, 5, 55-61. doi:10.1108/14636680310471299

[29] Rapaport, K., Stevens, M., Manthorpe, J., Hussein, S., Harris, J. and Martineau, S. (2008) Weighing the evidence: The case for using vignettes to elicit public and practitioner views of the workings of POVA vetting. The Journal of Adult Protection, 10, 6-17. doi:10.1108/14668203200800008

[30] Godet, M. (1987) Scenarios and strategic management. Butterworth, London.

[31] Godet, M. and Roubelat, F. (1996) Creating the future. Long Range Planning, 29, 164-171. doi:10.1016/0024-6301(96)00004-0

[32] Kalichman, S.C. Rompa, D. DiFonzo, K., Simpson, D. Kyomugisha, F., Austin, J. and Luke, W. (2001) Initial development of scales to assess self-efficacy for disclosing HIV status and negotiating safer sex in HIV+ persons. AIDS \& Behavior, 5, 291-296. doi:10.1023/A:1011300912395

[33] Bandura, A. (1995) Self-efficacy in changing societies. Cambridge University Press, New York. doi:10.1017/CBO9780511527692

[34] Forsyth, A.D. and Carey, M.P. (1998) Measuring Selfefficacy in the context of HIV risk reduction: Research challenges and recommendation. American Psychological Association, 17, 559-568.

[35] Maibach, E. and Murphy, D. (1995) Self-efficacy in health promotion research and practice: Conceptualization and measurement. Health Education Research, 10, 37-50. doi:10.1093/her/10.1.37

[36] Magowe, M.K.M. (2006) A qualitative study on beliefs and perceptions about health protective sexual communi- cation among young women aged 18 - 35 years, attending services at Gaborone city council clinics. Unpublished research report.

[37] Sandelowski, M. (2000) Focus on research methods: Whatever happened to qualitative description? Research in Nursing and Health, 23, 334-340. doi:10.1002/1098-240X(200008)23:4<334::AID-NUR9> 3.0.CO;2-G

[38] Parish, K.L., Cotton, D., Huszti, H.C. and Parsons, J.T. (2001) The hemophilia behavioral intervention evaluation group. Hemophilia, 7, 72-81. doi:10.1046/j.1365-2516.2001.00459.x

[39] Nuss, R., Smith, P.S., Cotton, D. and Kister, T. (1995) Communication about safer sex and serostatus disclosure in HIV positive adolescents with haemophilia. Haemophilia, 1, 126-130. doi:10.1111/j.1365-2516.1995.tb00053.x

[40] Janneke, H.H.M., van de Wijgert, A., Khumalo-Sakutukwa, G.N., Coggins, C., Dube, S.E., Nyamapfeni, P., Mwale M. and Padian, N.S. (1999) Men's attitudes towards vaginal microbicides and microbicide trials in Zimbabwe. International Family Planning Perspectives, 25, 15-20. doi:10.2307/2991897

[41] Svenson, G.R. and Hanson, B.S. (1998) Are peer and social influences important components to include in HIV-STD prevention models? European Journal of Public Health, 6, 203-211. doi:10.1093/eurpub/6.3.203

[42] Huszti, J.T., Parsons, D., Cotton, J., Mendoza, L., Harlow, K.L., Parish, L., Rich, R., Nuss, R. and Riske, B. (1998) Determinants of safer sex behavior in a long-term HIV infected population a national survey of men with hemophilia and HIV infection. Journal of Health Psychology, 3, 507-522. doi:10.1177/135910539800300405

[43] Crowell, T.L. (2004) Seropositive individuals' willingness to communicate, self-efficacy, and assertiveness prior to HIV infection. Journal of Health Education, 9, 394-424.

[44] Troth, A. and Peterson, C.C. (2000) Factors predicting safer sex talk and condom use in nearly sexual relationships. Health Communication, 12, 195-218. doi:10.1207/S15327027HC1202_5

[45] Cottrell, L., Li, X., Stanton, B., Harris, C., D’Alessandri, D., Sun, Z., Qu, M., Mao, R. and Zhang, H. (2006) Perceptions regarding preventive sexual practices and communication with sexual partners among Chinese college students. Preventive Medicine, 40, 189-196. doi:10.1016/j.ypmed.2004.05.019

[46] Moore, J.S., Harrison, J.S., Kay, K., Deren, S. and Doll, LS. (1995) Factors associated with Hispanic women's HIV-related communication and condom use with male partners. AIDS Care, 7, 415-427. doi:10.1080/09540129550126371 


\section{APPENDIX}

\section{Scenarios for Focus Group Discussions}

\section{Introduction and welcome:}

\section{Greetings (in Setswana): My name is}

I would like to start by welcoming you to this session and thank you very much for your interest in participating. This discussion is part of a study that seeks to explore your thoughts about how women in Botswana think regarding talking to their partner about safer sex. We the research team have developed some imaginary stories intended to stimulate your thoughts about situations in which sexual risk reduction communication needs to be initiated or sustained to enable you to discuss the issues in general without necessarily referring to yourselves, but how you think women in general may respond in the given situation. The stories do not refer to any one person. However they are based on real life stories of some women and may be possible occurrences for some of you. We would like to learn from you the possible answers you would have if you were in a similar situation. Please give as much information as you can in response to the questions that follow each story. We will read each of the stories and then ask you questions on the possible responses of women as you think about each situation presented. The questions focus on whether you think about the woman initiating the discussion, what you think her partner would say, what information think she should cover what difficulties she may encounter during the discussion with then partner and how she should address these. We would like to hear your honest views on these questions and to contribute as much as you can so that we can get to know what women in general would think or say. Please remember that you do not have to speak or respond to any question if you do not feel comfortable, and you can stop participating at any time. Also feel free to ask questions at any time if the information we give you is unclear or questions that follow are unclear.

By health protective sexual communication it means information that is of health protective nature introduced during intimate partner discussions including condom use, monogamy, conditional abstinence (when a partner has an STD or is on treatment for STD, or when there are other issues requiring temporary suspension of sexual relations between partners), sharing and requesting histories (number of sexual partners, STD and HIV statuses, use of drugs and alcohol), during discussions with a current or prospective sexual partner.

\section{Vignette 1: Potential sex partner:}

Imagine that a young woman has just met Mr. A who is definitely indicating that he wants to get closer to her. She senses that he is also interested in having sex with her as he is aggressively making definite sexual ad- vances. She is not yet used to this man but she thinks that it is important to talk about sexual risks with him before being involved sexually with him.

1) Do you think she would be able to engage in health protective sexual communication with this man? Please explain.

2) Tell us what you would suggest to her to get him to engage him in health protective sexual communication.

3) What topics would you suggest she should address in this discussion?

4) What Tactics would you advice her to use to initiate or sustain sexual risk discussions?

5) How do you think Mr. A would react to her discussions about sexual risk reduction?

6) What suggestions do you have for her to deal with his responses?

7) What difficulties do you anticipate she may have talking to him about sexual risks and why?

8) How would you suggest she deals with these difficulties? Please give specific examples and approaches.

\section{Vignette 2: Current sex partner:}

Imagine this young lady and Mr. A. have already had unprotected sex on several occasions, and she is really concerned about this, because she was at the clinic this morning where discussions about safer sex were held. She wants to make sure that the next sex episode is protected, and she prepares to talk to him about that. There have been no plans for long-term commitment or marriage in this relationship.

1) How would you advice her to approach this situation differently from the responses you gave in the first scenario?

Vignette 3: Committed sex partner, marriage anticipated, but partner is slick:

The young lady is now engaged to Mr. A. they are discussing about their anticipated happy life together. They have never really included safer sex in their discussions about sex. Mr. A is a very nice and loving person who is well versed with HIV/AIDS information, but has a tendency to gloat over safer sex discussions and simply ignores the use of sexual risk reduction strategies.

How do you feel about her discussing safer sex at this point?

1) What additional or different information and ap0 proaches would you suggest she use in this situation to discuss health protective sexual communication with him?

Vignette 4: Stable married partner, mature middleaged family:

Mr. D. is in a long-term committed partner, or married husband for many years and they have children. Both him and his partner are not anticipating any more children and have had surgical sterilization. However she has heard discussions that the risk of HIV among mar- 
ried and long-term partners is increasing in Africa. The couple has never discussed nor ever had a reason to suspect infidelity with one another, but she wants to talk about sexual risk reduction anyway just in-case something happens.

1) How do you feel about her starting this conversation with him?

2) How do you suggest she approach him?

3) What additional or different information and approach would you she uses in this situation to discuss safer sex with him?

Vignette 5: Married couples: partner suspected to be unfaithful:

The young woman married to Mr. D. above has heard rumors and suspects that Mr. D might be cheating on her.
1) What additional or different information or approaches would you suggest she should consider in discussing safer sex with this man?

Vignette 6: Married or committed relationship, partner has had an STD or is HIV positive:

The young lady who is married to Mr. D. above further discovers from his outpatient record that he has been diagnosed with an STD or that he has been tested for HIV and is positive.

1) How would you suggest she brings this up for discussion?

2) What additional or different information or approaches would you suggest she should address during this discussion with this man? 